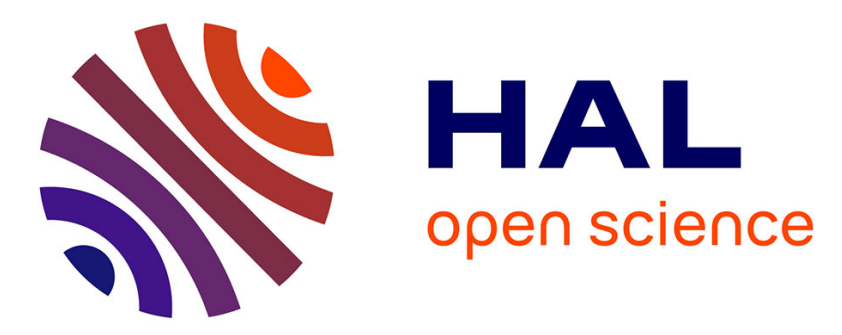

\title{
Advances in cyclic behavior and lifetime modeling of tempered martensitic steels based on microstructural considerations
}

\author{
Vincent Velay, Denis Delagnes, Gérard Bernhart
}

\section{To cite this version:}

Vincent Velay, Denis Delagnes, Gérard Bernhart. Advances in cyclic behavior and lifetime modeling of tempered martensitic steels based on microstructural considerations. Key Engineering Materials, 2008, 378-379, pp.81-100. 10.4028/www.scientific.net/KEM.378-379.81 . hal-01384451

\author{
HAL Id: hal-01384451 \\ https://hal.science/hal-01384451
}

Submitted on 19 Oct 2016

HAL is a multi-disciplinary open access archive for the deposit and dissemination of scientific research documents, whether they are published or not. The documents may come from teaching and research institutions in France or abroad, or from public or private research centers.
L'archive ouverte pluridisciplinaire HAL, est destinée au dépôt et à la diffusion de documents scientifiques de niveau recherche, publiés ou non, émanant des établissements d'enseignement et de recherche français ou étrangers, des laboratoires publics ou privés. 


\title{
Advances in cyclic behavior and lifetime modeling of tempered martensitic steels based on microstructural considerations.
}

\author{
V. Velay, D. Delagnes and G. Bernhart \\ Research Centre on Tools, Materials and Processes (CROMeP) \\ Ecole Mines Albi \\ Campus Jarlard, 81013 ALBI Cedex 09 \\ FRANCE \\ a vincent.velay@enstimac.fr, ${ }^{b}$ denis.delagnes@enstimac.fr, ${ }^{c}$ gerard.bernhart@enstimac.fr
}

Keywords: tempered martensitic steels, fatigue behavior modeling, life prediction, ageing, complex loading paths.

\begin{abstract}
Cyclic behavior and life prediction of two tempered martensitic steels (AISI H11 and L6) are investigated under thermo-mechanical loading conditions. Two non isothermal constitutive models developed in the same framework of the thermodynamics of irreversible processes are introduced. The first one, in relation with the tempering state, considers the fatigue-ageing phenomena whereas the second one is intended to take into account more complex loading paths. This last non unified approach allows to define different strain mechanisms which can be related to microstructural considerations. The strain-stress parameters provided by both approaches can be introduced into a lifetime model which is based on continuum damage mechanics.
\end{abstract}

\section{Introduction.}

Tempered martensitic steels are widely used in mechanical industry and in particular in tool and die manufacturing industry. These moulds are subjected to critical thermo mechanical loads very hard to assess from an experimental point of view. Numerical simulation seems to be adequate to provide the strain-stress response induced at different locations of the tool. It allows the introduction of a tool design optimisation strategy in order to improve its lifetime.

However, some prerequisites are mandatory. First, a cyclic elasto viscoplastic behavior model has to be identified from one dimensional fatigue tests. Complexity of its formulation depends on the complexity of the thermo-mechanical loading paths considered [1-7]. It may also be interesting to relate such a model to microstructural mechanisms observed (carbide coarsening and decrease of the dislocation density) [8] during fatigue in order to take into account ageing and fatigue-ageing interactions. Afterwards, all these parameters have to be introduced in a lifetime model whose values have themselves to be identified from uniaxial fatigue tests. Last, both of these approaches (behavior and damage models) need to be implemented into a finite element code in order to be validated in multi axial conditions and used for structure design.

This paper intends to give an overview of the research works performed over the last years on this topic in our research centre. In a first part the microstructural mechanisms responsible for the cyclic softening of tempered martensitic steels and fatigue rupture are recalled, and their relationship with the mechanical properties are described. Then the high temperature fatigue test program performed on two grades of martensitic steels and the optimised testing procedures are detailed in a second part. Based on experimental results, two behavior models - formulated in the general framework of 
irreversible processes - and able to consider cyclic softening, strain rate and dwell time effects were investigated [1-4] in more detail with the aim of introducing microstructural relationships:

- the first one $[5,26]$ introduces a ageing variable in order to take into account material microstructural evolution that occurs during tempering treatment and/or during high temperature working conditions. Indeed the hardness evolution of steels can become very important when the die-workpiece interface reaches temperature levels higher than the tempering temperature. In such conditions, steel may be subjected during its life to a continuous evolution of its microstructure and related properties.

- the second one $[1,18]$ intends to describe more complex fatigue loadings paths, like stress controlled tests and rachetting behavior and introduces two strain mechanisms able to follow the contribution of the two main microstructural contribution observed in this steels during fatigue, i.e. dislocation density decrease and carbide coarsening.

The final part describes the high temperature fatigue lifetime model that was developed and identified. It is based on a continuum damage approach [12-14] that considers the stress as a critical value for damage evolution. The reduced stress approach allows the definition of a Woehler master curve that simplifies identification and that can be used for anisothermal lifetime prediction $[17,18]$.

\section{Microstructural aspects.}

\section{Fatigue behavior.}

As fatigue is one of important cause of tool steel damage, it is of great importance to have a clear understanding of fatigue behavior mechanisms. Nevertheless, probably due to experimental difficulties, microstructural parameters (connected with small secondary carbides and dislocations inherited from the quench) giving suitable mechanical properties after heat treatment and during fatigue are never totally investigated. Notably, martensitic or bainitic steels have a typical fatigue behavior as these steels present a strong softening effect till rupture (see Fig. 1). Amplitudes of softening depend on the chemical composition, the heat treatment and testing conditions. This strong effect (which may lead to a softening reaching $25 \%$ of the stress amplitude measured at the first cycle) associated to microstructure evolution is scarcely described in the literature. If the stress amplitude is plotted versus the number of cycles, this softening can be divided in three successive stages (Fig. 1). Indeed, the strong softening stage occurring during the first hundred cycles is followed by a pseudo-stability one (weak softening) during the major part of the lifetime. At the end, crack propagation occurs, defined by a fast decrease of the stress amplitude before the rupture $[1,8]$. With the metallic matrix, major characteristics of the microstructure of tempered martensitic steels are prior austenic grains, martensitic laths, carbides and dislocations. These microstructural elements range several orders of magnitude in size from several microns (prior austenitic grain) to nanometer (secondary hardening carbides). Die material development requires the optimisation of each elements in order to achieve special properties for each application. Recent studies $[8,15]$ have shown that prior austenitic grain and lath average sizes were not influenced by the tempering and fatigue loading for the temperature range investigated $\left(0^{\circ} \mathrm{C}\right.$ to $\left.600^{\circ} \mathrm{C}\right)$. Conversely, the high dislocation density inherited from the quench is involved in the fatigue softening. Indeed, after tempering, dislocations distribution is quite homogeneous even if, at a nanometric scale, a concentration of dislocations has been observed on prior austenitic grain, lath boundaries and around carbides. After few cycles, the dislocations tangles is gradually crushed and the dislocation structure becomes heterogeneous with high and strongly reduced density zones when the pseudo stabilisation occurs. Such a configuration promotes a free dislocations movement between the high density zones (free slip distances are increased) promoting the increase of plastic deformation (i.e. cyclic softening). For low total strain amplitude, such dislocation structure is not so well formed and is still incomplete when specimen rupture occurs. Therefore, these observations $[8,15]$ may explain 
the lack of cyclic saturation. Moreover, cross glide and dislocations climb mechanisms inducing dislocations annihilation may contribute to cyclic softening.

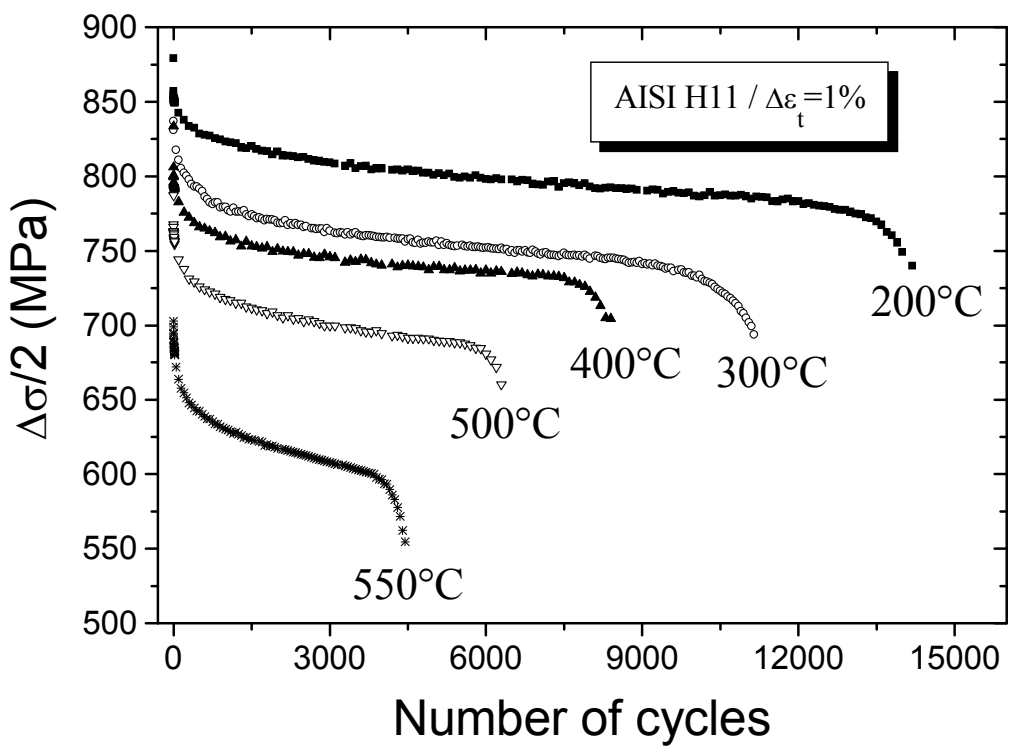

Figure 1 : Fatigue behaviour of the AISI H11 steel

At high temperatures, iron, chromium and vanadium carbides coarsening takes place inducing a huge loss of their number density reducing therefore the number of obstacles to the dislocation arrangement resulting in a fast recovery of the microstructure. This mechanism promotes dislocations mobility and reduces the steel resistance due to the fine precipitation occurring during tempering. So, carbides coalescence also contributes to cyclic softening $[8,16]$.

\section{Fatigue life.}

Qualitative SEM (Scanning Electron Microscope) examinations were performed (fracture surfaces and longitudinal observations) in order to investigate the fracture mechanisms. Fatigue specimens were chosen in order to enhance either the fatigue damage (transgranular) and either the creep damage (intergranular) mechanisms. So, post mortem observations were carried out on samples FTRT, CRT and TRT (see Fig. 2). Test conditions seem to be adequate to develop both kinds of damage mechanisms depending on strain rate and temperature.

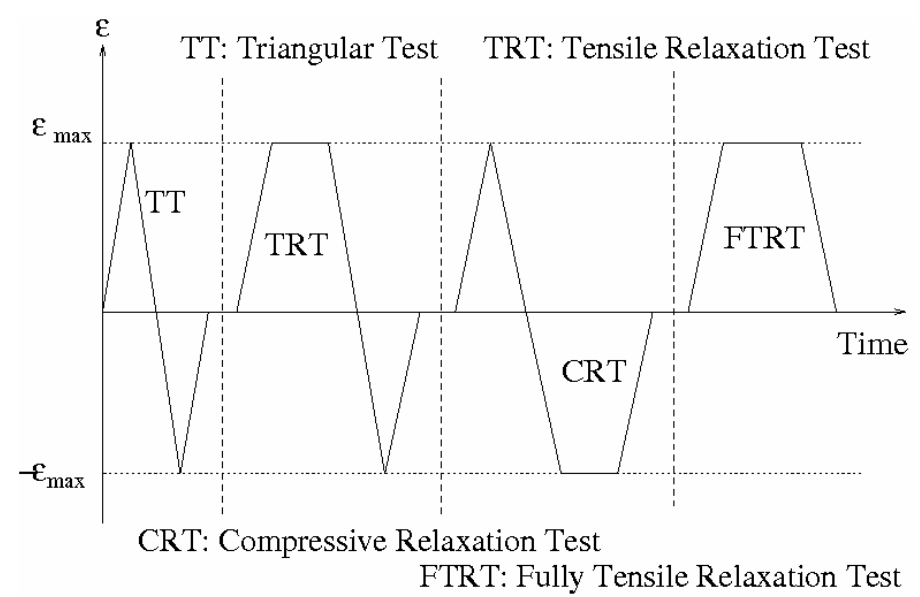

Figure 2: Description of the cyclic loadings 
Within our testing conditions, intergranular damage was never observed on AISI H11 steel [17-19], indeed, all the observations have shown a transgranular propagation of cracks (damage due to the fatigue process) perpendicular to the loading direction. Some crack initiations within the specimen were also observed. Two kinds of cracks can be seen on such steel [15-16]: thin cracks that seem to propagate along the martensitic lath boundaries and very wide cracks not influenced by the microstructure. Fatigue striation zones appear on the fracture surfaces; they depend on the test strain range and are very difficult to observe for the small strain amplitudes. On the contrary, striation spacing measurements allow to determine the crack propagation history for the high strain amplitudes [20].

Crack initiation mechanisms are more complex to determine. Indeed, the oxide layer often makes difficult microscopic observations. So, it is very hard to differentiate the oxide intrusion from the thin crack initiation. However, three initiation mechanisms were observed [19]:

- Non Metallic Inclusion NMI

- Lath boundaries

- Grain boundaries of the initial austenitic microstructure

These mechanisms were quantified for several temperature conditions. So, NMI and lath boundary initiation proportion decreases with increasing test temperature whereas the grain boundary initiation increases. This mechanism, negligible for the temperature below $400^{\circ} \mathrm{C}$, reaches a proportion of $30 \%$ at $500^{\circ} \mathrm{C}, 65 \%$ at $550^{\circ} \mathrm{C}$ and $90 \%$ at $600^{\circ} \mathrm{C}$ [19] (see Fig. 3).

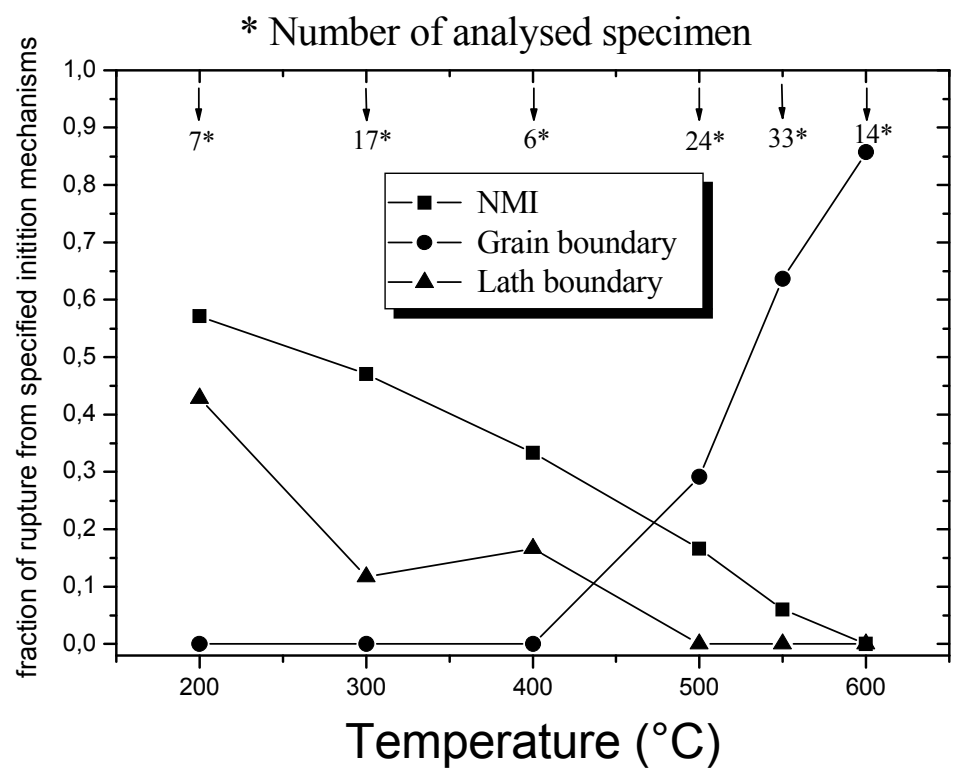

Figure 3: Main fatigue crack initiation sites as a function of the testing temperature

Some examinations around the fracture surface allow to exhibit the martensitic microstructure, as the oxide layer is spread away during the sample rupture. Thus, the martensite laths which are located within the grains of the initial austenitic structure can be observed; a grain decohesion seems to appear and an intergranular crack initiation could be suggested [17-18]. Crack growth observed on AISI H11 steel are transgranular whatever the test conditions, selected to be close to in-service tool conditions. Additional SEM examinations seem nevertheless necessary to investigate in more detail the crack initiation mechanisms. 


\section{Experimental.}

An extended testing program, involving more than 150 samples, was conducted over a few years. It concerns two steel grades, several initial hardness (i.e. tempering treatments), isothermal and anisothermal conditions, temperatures ranging between room temperature and $600^{\circ} \mathrm{C}$ and various type of fatigue cycles (strain rates, stain amplitudes, dwell times, ...). Materials and test program are summarized in the following.

\section{Heat Treatment.}

The chemical composition of the investigated steels is given in Table 1. For the AISI H11 steel, heat treatments includes austenitizing at $980^{\circ} \mathrm{C}$ for $1 \mathrm{~h}$ followed by air cooling, a first tempering at $550^{\circ} \mathrm{C}$ for $2 \mathrm{~h}$ and a second tempering at $605^{\circ} \mathrm{C}$ for $2 \mathrm{~h}$ resulting in a tempered martensitic structure with a measured hardness level equal to $470 \mathrm{HV}_{0.2}$. For the AISI L6 steel, austenitization was performed at $850^{\circ} \mathrm{C}$ for $1 \mathrm{H}$ followed by a single tempering for $2 \mathrm{~h}$ at $350^{\circ} \mathrm{C}, 460^{\circ} \mathrm{C}, 560^{\circ} \mathrm{C}$ and $600^{\circ} \mathrm{C}$ resulting in a tempered martensitic structure with a measured hardness level, respectively equal to $580 \mathrm{HV}_{0.2}$, $509 \mathrm{HV}_{0.2}, 457 \mathrm{HV}_{0.2}$ and $376 \mathrm{HV}_{0.2}$. These tempering conditions correspond to the usual steel states required for industrial applications.

\begin{tabular}{|c|c|c|c|c|c|c|c|}
\hline Grades & $\mathrm{C}$ & $\mathrm{Si}$ & $\mathrm{Mn}$ & $\mathrm{Ni}$ & $\mathrm{Cr}$ & $\mathrm{Mo}$ & $\mathrm{V}$ \\
\hline AISI H11 & 0.36 & 0.3 & 0.35 & 0.06 & 5.1 & 1.25 & 0.5 \\
\hline AISI L6 & 0.56 & 0.2 & 0.7 & 1.7 & 1.0 & 0.5 & 0.1 \\
\hline
\end{tabular}

Table 1. Chemical composition (wt.\%) of the investigated steels

\section{Experimental Procedure.}

This procedure is divided into two sections. The first one includes the investigation of the various complex thermo-mechanical loading paths that may be induced into the tools during working conditions. At this stage, two different martensitic steels (AISI L6 and H11) are investigated and the fatigue damage of the material is not considered. A detailed fatigue lifetime investigation of AISI H11 martensitic steel is performed in the second one. Hence, loading conditions related to number of cycles to failure can be discussed.

\section{Testing methology for behavior model identification.}

The low cycle fatigue tests were carried out with a MTS servo-hydraulic testing machine and Testar II $^{\mathrm{TM}}$ controller connected to a computer. Heating was achieved with an induction coil. A more detailed description of the experimental setup can be found in a previous work [1]. The AISI L6 steel was tested with different tempering temperatures which confer to the material different hardness levels $\left(580 \mathrm{HV}_{0.2}, \quad 509 \mathrm{HV}_{0.2}, \quad 457 \mathrm{HV}_{0.2}\right.$ and $\left.376 \mathrm{HV}_{0.2}\right)$. On the other hand, AISI H11 steel was also investigated but for only one hardness level $\left(470 \mathrm{HV}_{0.2}\right)$. In this case, the purpose was not to investigate the influence of hardness on the mechanical behavior but to induce several complex loading conditions close to those that may appear during hot forming operations. Both of them were investigated in isothermal fatigue conditions for temperatures ranging from $20^{\circ} \mathrm{C}$ to $600^{\circ} \mathrm{C}$.

In order to reduce number of test specimens and to decrease manpower and time required for model parameter identification, an optimized test procedure was developed over the years. For each temperature $\left(20\right.$ to $600^{\circ} \mathrm{C}$ ) and material hardness, it requires only two material samples, the first subjected to the type I test and the second to type II test. The corresponding procedures are described in more detail in the following [1,3]. 


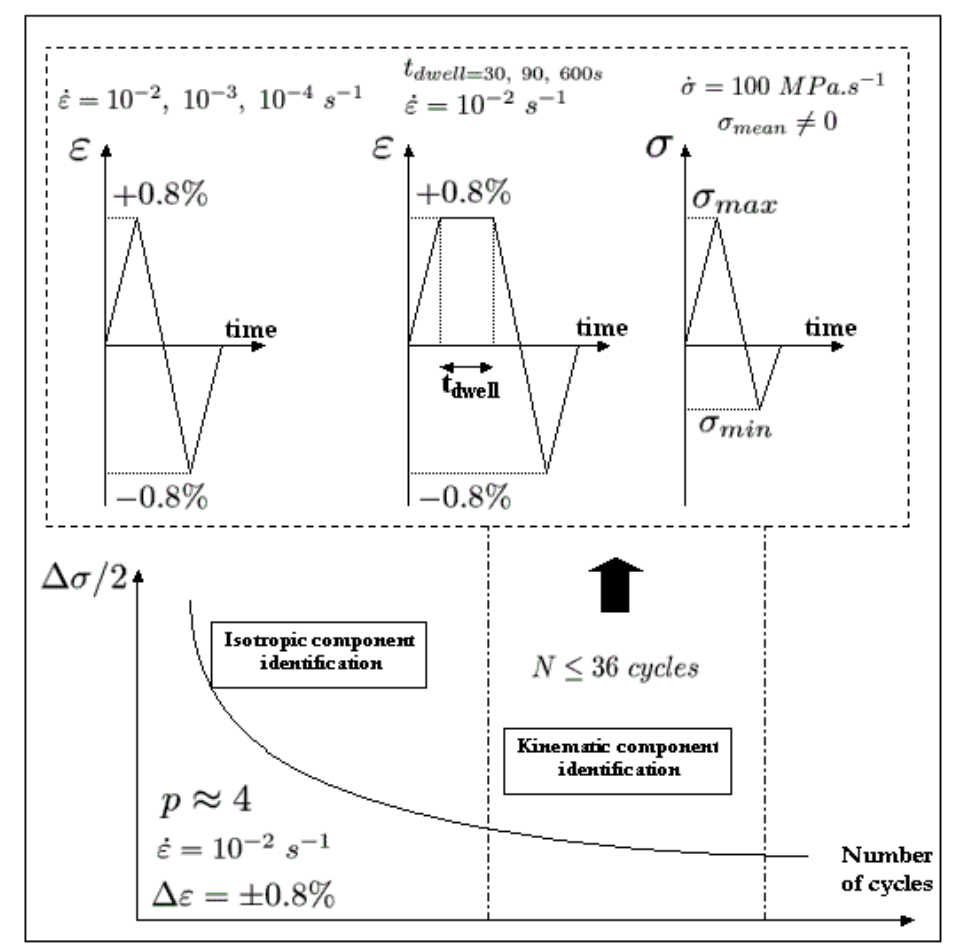

Figure 4 : Type I test and related identification methodology

The type I test (Fig. 4) may be itself divided into two different steps:

- the step 1 is a symmetrical total strain controlled push-pull low cycle fatigue test, with a fixed strain range $\Delta \varepsilon_{\text {tot }}=1.6 \%$, itself divided in three sub-steps.

- Sub-step 1 consists in a number of fatigue cycles so as to reach a cumulative plastic strain $\mathrm{p}$ close to 4 at a constant strain rate of $10^{-2} \mathrm{~s}^{-1}$. This part is illustrated on Fig. 5a for different temperature levels and L6 steel. The test temperature has a great impact on the behavior. The cyclic softening amplitude decreases from $20^{\circ} \mathrm{C}$ to $300^{\circ} \mathrm{C}$ and then increases from the temperature of $300^{\circ} \mathrm{C}$ to $500^{\circ} \mathrm{C}$. For this grade the linear part of the softening is not influenced by the temperature. This is not the case for H11 steel where the linear softening increases when temperature rises [1].

- During the sub-step 2, strain rate is varied from $10^{-2}$ to $10^{-3}$ and $10^{-4} \mathrm{~s}^{-1}$ and three cycles are performed at each strain rate in order to stabilize the cycle. Fig. $5 \mathrm{~b}$ illustrates this effect for H11 steel at $600^{\circ} \mathrm{C}$. At high temperature, the strain rate effect highlights a decrease of the stress amplitude with a decrease of the strain rate.

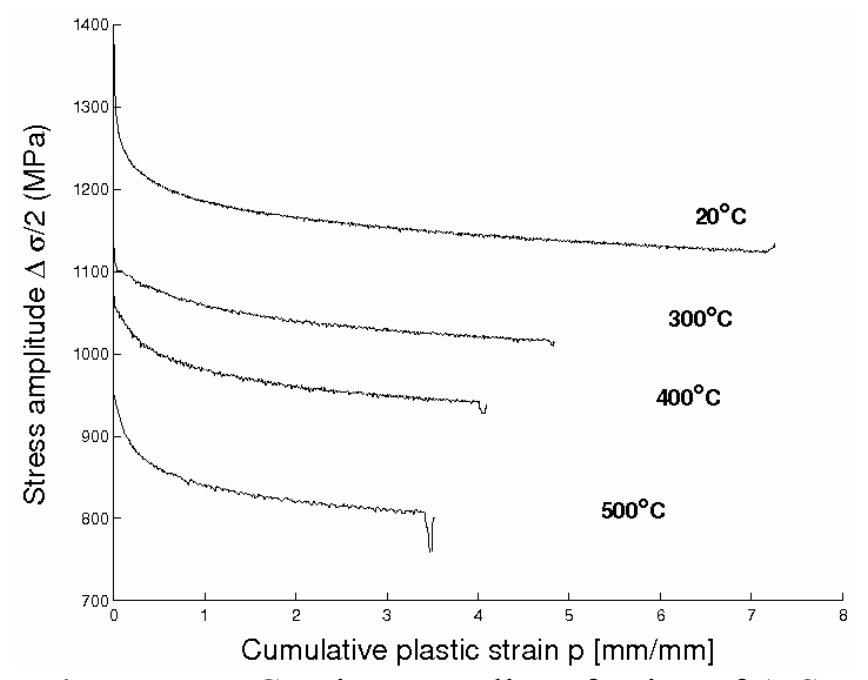

Figure 5: a- Continous cyclic softening of AISI L6 martensitic steel

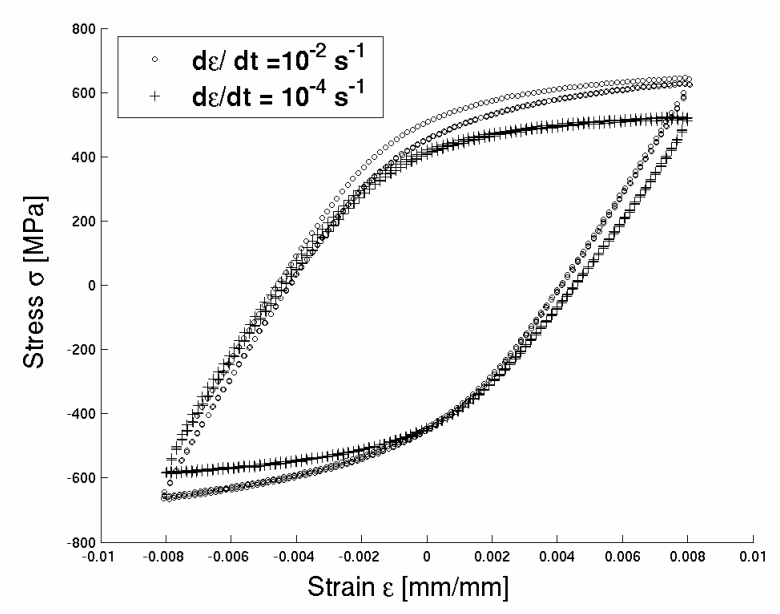

b- Strain rate effect (AISI H11 steel, $\mathrm{T}=600^{\circ} \mathrm{C}$ ) 


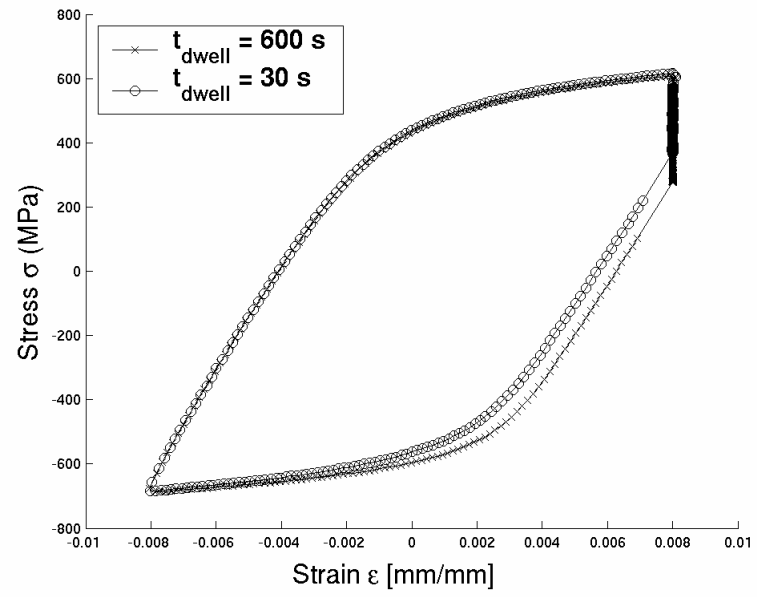

Figure 6: a- Dwell time effect (AISI H11 steel, $\left.\mathrm{T}=600^{\circ} \mathrm{C}\right)$

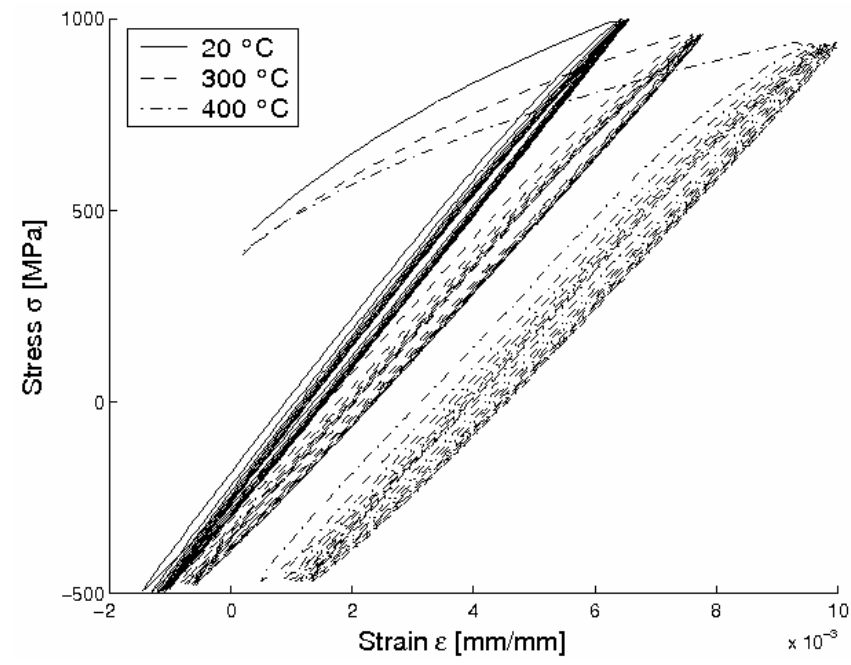

b- Plastic shakedown effect (AISI L6 steel)

- At last (sub-step 3), fatigue relaxation cycles are included with a strain rate of $10^{-2} \mathrm{~s}^{-1}$, whereas relaxation time is varied from $30 \mathrm{~s}$ ( 3 cycles) to $90 \mathrm{~s}$ and $600 \mathrm{~s}$ ( 2 cycles for each one). An example of fatigue relaxation loops is plotted on Fig. 6a for AISI H11 steel and a temperature of $600^{\circ} \mathrm{C}$. The dwell time effect (Fig 6a) is also a time dependent effect which is activated with the temperature. Indeed the stress relaxation during the dwell time is increased when dwell time increases.

- the step 2 consists in a non-symmetrical stress controlled fatigue test (10 cycles) at a constant stress rate of $100 \mathrm{MPa}$.s-1. Depending on the stress amplitude applied, such stress controlled test leads to a progressive strain increase. The stress amplitude applied can induce either a stabilization (plastic shakedown, Fig. 6b) either an increase of the cyclic strain at each cycle (ratcheting, Fig. 7a).

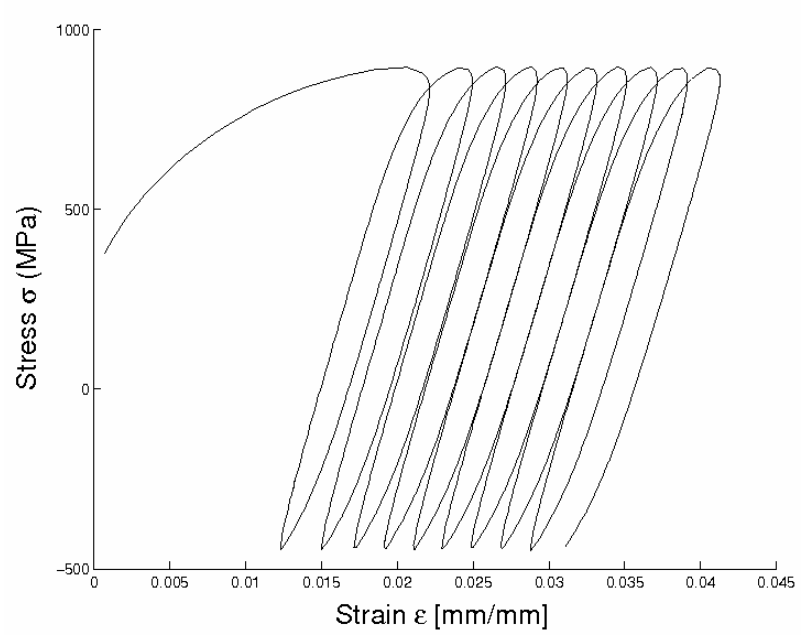

Figure 7: a- Ratchetting effect (AISI L6 steel, $\left.\mathrm{T}=500^{\circ} \mathrm{C}\right)$

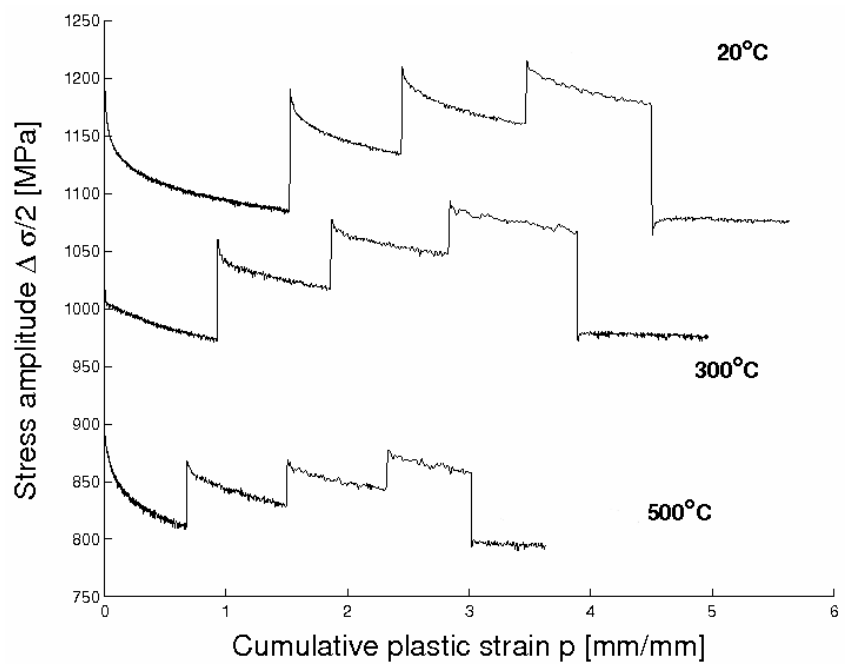

b- Multi-stage cyclic softening of AISI L6 martensitic steel

The type II test (Fig. 7b) consists in a symmetrical total strain fatigue test at constant strain rate of $10^{-2} \mathrm{~s}^{-1}$, in which strain range is varied from $\pm 0.6 \%$, to $\pm 0.7 \%, \pm 0.8 \%$ and $\pm 0.9 \%$ before coming back to $\pm 0.7 \%$. The number of cycles is selected so as to reach a cumulative plastic strain $p$ close to 1 for each strain range applied. This test is intended to identify the strain memory effect of 
plastic strain path history. Thus, after several cycles leading to the linear part of the softening, an increase of the strain amplitude implies a new strong softening. On the contrary, a decrease of this amplitude provides a linear softening.

All parameters of these tests have been carefully selected in oder to cover the typical loads expected on dies when used in various hot forming processes and, as a consequence, to give a general validity of the model wathever the forming process. Indeed, the high strain rates (about $10^{-2} \mathrm{~s}^{-1}$ ) is intended to reproduce loads occurring in mechanical forging or casting industry, whereas the low strain rates (about $10^{-4} \mathrm{~s}^{-1}$ ) to take into account those of the hydraulic forging. The dwell times included in the fatigue loops are requested to describe the extrusion processes. Stress controlled tests intend to cover structure effects.

\section{Fatigue life testing.}

Low cycle fatigue tests were carried out with Shenck Hydropuls servo hydraulic testing machine, heating was achieved with a resistive furnace. Here only AISI H11 steel with a nominal hardness of $470 \mathrm{HV}_{0.2}$ was investigated in detail [17]. Some results are nevertheless available on L6 steel $\left(457 \mathrm{HV}_{0.2}\right)$ in reference [4]. An automatic process was implemented in order to calculate the relevant values of a cycle as total and plastic strains, stresses, cumulative plastic strain. Experimental data used to identify the lifetime model, include 46 total strain controlled low cycle fatigue tests for temperature levels between $300^{\circ} \mathrm{C}$ and $600^{\circ} \mathrm{C}$. Some of them were performed at a very low frequency $\left(\dot{\varepsilon}=10^{-3} \mathrm{~s}^{-1}\right)$ including tensile and compressive dwell times (60 and $90 \mathrm{~s}$ ) [17$19]$ as described in Fig. 2. High frequency low cycle tests were considered for the other tests with strain rates about $\dot{\varepsilon}=10^{-2} \mathrm{~s}^{-1}$. Thus, test conditions investigated include a very broad temperature and strain rate range and contribute to give an important validity domain for the model. Indeed test conditions as temperature, frequency and strain range can affect lifetime.

Major results gained from the tests are summarized in the following. For the same strain ranges, an increase of the temperature implies a decrease of stress level, a more important cyclic softening intensity and shorter lifetimes. Cyclic softening intensity increases and lifetime decreases when higher strain levels are considered whereas cumulative plastic strain decreases. For very low loadings, the strong softening which normally occurs during the first hundred of cycles completely vanishes. Dwell times and strain rates have a significant effect on lifetimes. At high temperature, the more strain rate is low, the more cyclic softening intensity is important. Moreover, lifetime is greatly reduced by a decrease of the test frequency. Dwell times also introduce time dependent effects and thus, affect the lifetime.

Experimental Woehler curves are presented in Fig. 8 for different temperature levels. For similar test conditions (temperature and strain amplitude), it can be concluded that lifetime decreases when strain rate decreases and that stress levels decrease when test temperature increases. However, test conditions have low effect on the slopes of the Woehler curves. A complete and detailed description of each test (Young moduli, number of cycles to failure, strain and stress ranges or amplitudes at mid-life...) can be found in references [17] and [18]. 


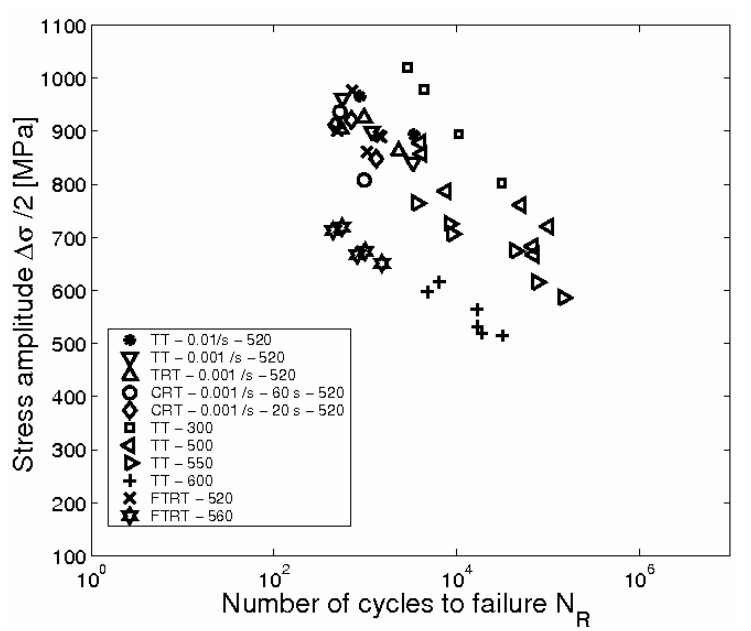

Figure 8: Woehler curve including all the lifetime fatigue test performed

\section{Modeling.}

Experimental procedure and results reported in the previous section, were used to develop a methodology able to identify the cyclic behavior of martensitic steels under complex loadings and to assess their lifetimes in these conditions.

\section{Fatigue Behavior modeling.}

Different models were developed to describe the behavior of martensitic tool steels $[1-5,18]$. They were based on several constitutive equations formulated within the theoretical framework of the thermodynamics of the irreversible processes [11]. This theory assumes that the evolution of a material system can be described as a succession of equilibrium states. It introduces two sets of variables. The observable (like total strain or temperature) and the internal variables (intended to describe internal material evolution) allow to define completely a material element and its evolution over time and temperature. In the classical viscoplastic theory total strain can be partitioned into elastic and inelastic ones. The model equations were determined from the free energy potential $\psi$ used to define the state laws and from the dissipation potential $\Omega$ used to define the evolution equations. Many works have investigated such kinds of approaches in order to develop behavior models for metallic materials used in various industrial applications [10-11,21-25].

\section{Behavior model including material ageing evolution.}

Two models were successively developed on AISI L6 steel (and also applied to H11 steel). The first one $[1,3,18]$ was a non isothermal approach able to take into account the strain rate effect induced at high temperature and the cyclic softening of the material. The second one $[5,26]$ moreover includes microstructure evolutions when testing temperature exceeds the tempering temperature of the steel. For that purpose, a new internal scalar variable $\tau_{\mathrm{v}}$ (tempering ratio) related to the steel ageing was introduced into the different potentials, its associated variable was called Z. Considering ageing fatigue, free energy was derived in the following form:

$$
\rho \Psi\left(\underline{\varepsilon_{e}}, \underline{\alpha_{j}}, r_{j}, \tau, T\right)=\frac{1}{2} \underline{\varepsilon_{e}} \underline{\underline{C}: \underline{\varepsilon_{e}}}+\sum_{i=1}^{2} \frac{1}{3} C_{i} \underline{\alpha_{i}:} \underline{\alpha_{i}}+\frac{1}{2} Q_{1} r_{1}^{2}+\frac{1}{2} b Q_{2}(q) r_{2}^{2}+\frac{L}{2}\left(1-\tau_{v}\right)^{2}
$$


where $\mathrm{C}_{\mathrm{i}}, \mathrm{Q}_{\mathrm{i}}, \mathrm{b}, \mathrm{L}$ are scalar model parameters depending on temperature and steel grade, $\underline{\alpha}_{i}, \mathrm{r}_{\mathrm{i}}, \square_{\mathrm{v}}$ internal variables $(\mathrm{i}=1,2)$. The following variables $\underline{X}_{i}, \mathrm{R}_{\mathrm{i}}, \mathrm{Z}$ are their associated variables, $\mathrm{q}$ is the strain memory variable. $\underline{\underline{C}}$ is the fourth order Hooke's tensor. Last, the unified approach considers the partition of the total stain tensor into an elastic and inelastic parts, $\underline{\varepsilon}_{t}=\underline{\varepsilon}_{e}+\underline{\varepsilon}_{p}$.

From equation (1), the state laws can be derived:

$$
\begin{gathered}
\underline{\sigma}=\rho \frac{\partial \Psi}{\partial \underline{\varepsilon}_{e}}=\underline{\underline{C}} \underline{\varepsilon}_{e} ; \quad \underline{X}_{i}=\rho \frac{\partial \Psi}{\partial \underline{\alpha}_{i}}=\frac{2}{3} C_{i} \underline{\alpha}_{i} ; \quad \mathrm{R}_{1}=\rho \frac{\partial \Psi}{\partial r_{1}}=Q_{1} r_{1} ; \\
\mathrm{R}_{2}=\rho \frac{\partial \Psi}{\partial \mathrm{r}_{2}}=\mathrm{bQ}_{2}(\mathrm{q}) \mathrm{r}_{2} ; \quad \mathrm{Z}=\rho \frac{\partial \Psi}{\partial \tau_{\mathrm{v}}}=-\mathrm{L}\left(1-\tau_{\mathrm{v}}\right)
\end{gathered}
$$

The micro-structure change, i.e evolution of tempering ratio $\tau_{\mathrm{v}}$, is associated to an ageing potential $\Omega_{\mathrm{a}}[5,13,26]$. Therefore, total dissipation potential can be divided into ageing potential $\Omega_{\mathrm{a}}$ and viscoplastic potential $\Omega_{\mathrm{vp}}$ :

$$
\Omega=\Omega_{v p}\left(\sigma, \underline{X}_{i}, R_{j} ; \underline{\alpha}_{j}, r_{j}, p, T\right)+\Omega_{a}\left(\mathrm{Z} ; \tau_{\mathrm{v}}, T\right)
$$

Visco-plastic dissipation potential is selected in the form $[1,5]$ :

$$
\Omega_{v p}=\frac{K}{n+1}\left\langle\frac{f}{K}\right\rangle^{n+1} \quad \text { where } \mathrm{f}=\mathrm{G}+\sum_{\mathrm{i}=1}^{2}\left(\frac{3}{4} \frac{D_{i}}{C_{i}} \underline{X}_{i}: \underline{X}_{i}-\frac{1}{3} C_{i} D_{i} \underline{\alpha}_{i}: \underline{\alpha}_{i}\right)+\frac{R_{2}^{2}}{2 Q_{2}}-\frac{b^{2} Q_{2} r_{2}^{2}}{2}
$$

and $G=J_{2}(\underline{\sigma}-\underline{X})-R_{1}-R_{2}-R_{0}$ defines the Von Mises type yield surface with $\underline{X}=\sum_{i=1}^{2} \underline{X}_{i}$ and $J_{2}(\underline{\sigma}-\underline{X})=\sqrt{\frac{3}{2}\left(\underline{\sigma}^{\prime}-\underline{X}\right):\left(\underline{\sigma}^{\prime}-\underline{X}\right)}$ where $\underline{X}$ and $\underline{\sigma}^{\prime}$ correspond to the deviatoric parts of $\underline{X}$ and $\underline{\sigma}$ and $\mathrm{K}, \mathrm{n}$ and $\mathrm{R}_{0}$ are temperature and steel grade dependant parameters. In order to allow the introduction of the dynamic recovery terms and the non-linear isotropic variables, additional terms, depending on internal variables $\left(\alpha_{i}, r_{i}\right)$ and considered as parameters, can be added [11]. These extra-terms vanish using the state laws (2).

Ageing potential was proposed in the form: $\Omega_{a}=\frac{Z^{2}}{2 L} t^{m-1}$

and from equation (4), plastic rate evolution is:

$$
\dot{\dot{\varepsilon}}_{p}=\frac{\partial \Omega}{\partial \underline{\sigma}}=\frac{3}{2} \dot{p} \frac{\underline{\sigma}^{\prime}-\underline{X}}{J_{2}(\underline{\sigma}-\underline{X})}
$$

where $\dot{p}=\left\langle\frac{f}{K}\right\rangle^{n}=\sqrt{\frac{2}{3} \underline{\dot{\varepsilon}}_{p}: \underline{\dot{\varepsilon}}_{p}}$ is the cumulative plastic flow rate.

Moreover, flow rules of the internal variables (back stress and drag stress) are written as follows:

$$
\underline{\dot{\alpha}_{i}}=-\frac{\partial \Omega}{\partial \underline{\mathrm{X}_{\mathrm{i}}}}=\underline{\dot{\varepsilon}}_{p}-D_{i} \underline{\alpha}_{i} \dot{p} ; \dot{r}_{1}=-\frac{\partial \Omega}{\partial \mathrm{R}_{1}}=\dot{p} \text { and } \dot{r}_{2}=-\frac{\partial \Omega}{\partial R_{2}}=\dot{p}\left(1-b r_{2}\right) ; \mathrm{i}=1,2
$$


Ageing variable flow equation is derived from expression (5):

$$
\dot{\tau}_{v}=-\frac{\partial \Omega}{\partial Z}=-\frac{Z}{L} t^{m-1} m D^{m}=\left(1-\tau_{v}\right) t^{m-1} m D^{m}
$$

Under this assumption of decoupling the thermal dissipation and intrinsic dissipation, the second principle can be written as:

$\Theta=\underline{\sigma}: \underline{\dot{\varepsilon}}_{p}-\sum_{i=1}^{2}\left(\underline{X}_{i}: \underline{\dot{\alpha}}_{i}-R_{i} \dot{r}_{i}\right)-Z \dot{\tau}_{v}=G \dot{p}+\dot{p} \sum_{i=1}^{2}\left(\frac{D_{i}}{C_{i}} J\left(\underline{X}_{i}\right)^{2}\right)+\left(R_{0}+\frac{R_{2}^{2}}{Q_{2}}\right) \dot{p}+\frac{Z^{2}}{L} m D^{m} t^{m-1} \geq 0$

where the first three terms correspond, respectively, to viscous, kinematic and isotropic flow dissipations. The last one represents the ageing dissipation of the steel. Intrinsic dissipation is always positive and shows that the model formulation is in agreement with thermodynamic principles.

\section{Behavior model including complex loading paths.}

In this case, the same thermodynamic framework was preserved. Free energy potential and dissipation potential were slightly modified in order to take into account more complex loading paths (ratchetting, plastic shakedown and dwell time effects). However, ageing effect was not included anymore into this formulation. This model named Two (strain) Mechanisms and one (yield) Criterion (2M1C) [9-10] was successfully applied on AISI L6 and AISI H11 martensitic steels $[1,18]$.

$$
\begin{aligned}
& \rho \Psi=\rho \Psi_{e}\left(\underline{\varepsilon}_{e}, T\right)+\rho \psi_{i n}\left(\alpha_{j}, r_{j}, T\right) \text { where : } \\
& \rho \Psi_{e}\left(\underline{\varepsilon_{e}}, T\right)=\frac{1}{2} \underline{\varepsilon_{e}} \underline{\underline{C}} \underline{\underline{\varepsilon_{e}}} \text { and } \rho \Psi_{i n}=\frac{1}{3}\left(\underline{\alpha}_{1} \underline{\alpha}_{2}\right)\left(\begin{array}{ll}
C_{11} & C_{12} \\
C_{12} & C_{22}
\end{array}\right)\left(\begin{array}{l}
\underline{\alpha}_{1} \\
\underline{\alpha}_{2}
\end{array}\right)+\frac{1}{2}\left(\begin{array}{ll}
r_{1} & r_{2}
\end{array}\right)\left(\begin{array}{ll}
b_{11} Q_{11} & b_{21} Q_{12} \\
b_{12} Q_{12} & b_{22} Q_{22}
\end{array}\right)\left(\begin{array}{l}
r_{1} \\
r_{2}
\end{array}\right)
\end{aligned}
$$

Within such a formulation, the inelastic part of the free energy definition involves different state coupling (kinematic-kinematic, kinematic-isotropic, isotropic-isotropic) that could be related to several mechanisms as for example a low and a high dislocation density [9-10]. Coefficients $\mathrm{C}_{\mathrm{ij}}, \mathrm{b}_{\mathrm{ij}}$, $\mathrm{Q}_{\mathrm{ij}}$ are temperature and material dependant parameters. Internal and associated variables remain the same as in the previous formulation except for the ageing variables that vanishes. This formulation considers a non unified approach where total strain tensor is partitioned into an elastic and an inelastic strain, itself related to a linear combination of two elementary inelastic strain mechanisms.

$$
\underline{\varepsilon}_{t}=\underline{\varepsilon}_{e}+\underline{\varepsilon}_{i n} \text { where } \underline{\varepsilon}_{i n}=A_{1} \underline{\varepsilon}_{1}+A_{2} \underline{\varepsilon}_{2}
$$

Each strain mechanism is associated to a stress state resulting from the free energy potential (9):

$$
\begin{aligned}
& \underline{\sigma}=\rho \frac{\partial \Psi}{\partial \underline{\varepsilon}_{e}}=\underline{C}_{\underline{\varepsilon}} ; \underline{\sigma}_{1}=-\rho \frac{\partial \Psi}{\partial \underline{\varepsilon}_{1}}=A_{1} \underline{\sigma} \text { and } \underline{\sigma}_{2}=-\rho \frac{\partial \Psi}{\partial \underline{\varepsilon}_{2}}=A_{2} \underline{\sigma} \\
& \underline{X}_{1}=\rho \frac{\partial \Psi}{\partial \underline{\alpha}_{1}}=\frac{2}{3}\left(C_{11} \underline{\alpha}_{1}+C_{12} \underline{\alpha}_{2}\right) \text { and } \underline{X}_{2}=\rho \frac{\partial \Psi}{\partial \underline{\alpha}_{2}}=\frac{2}{3}\left(C_{12} \underline{\alpha}_{1}+C_{22} \underline{\alpha}_{2}\right) .
\end{aligned}
$$


Moreover, if no coupling is considered for the isotropic variables $\left(b_{12}=0\right)$, then:

$$
R_{1}=\rho \frac{\partial \Psi}{\partial r_{1}}=b_{11} Q_{11} r_{1} \text { and } R_{2}=\rho \frac{\partial \Psi}{\partial r_{2}}=b_{22} Q_{22} r_{2}
$$

In order to take into account the tensile or compressive dwell times within fatigue loops, dissipation potential can be divided into a time recovery potential $\Omega_{\mathrm{r}}$ and a viscoplastic potential $\Omega_{\mathrm{vp}}$

$$
\Omega=\Omega_{v p}\left(\underline{\sigma}, \underline{X}_{i}, R_{j} ; \underline{\alpha}_{j}, r_{j}, p, T\right)+\Omega_{r}\left(\underline{X}_{i}\right)
$$

Viscoplastic potential is similar as previously, and time recovery potential can written as:

$$
\Omega_{r}=\sum_{i=1}^{2} \frac{M_{i}}{m_{i}+1}\left\langle\frac{J_{2}\left(\underline{X}_{i}\right)}{M_{i}}\right\rangle^{m_{i}+1}
$$

In this case, the yield criterion can be re-written as:

$$
\begin{aligned}
\mathrm{f}=\mathrm{G} & +\frac{3}{4} \frac{D_{1}}{C_{11}} \underline{X}_{1}: \underline{X}_{1}+\frac{3}{4} \frac{D_{2}}{C_{22}} \underline{X}_{2}: \underline{X}_{2}-\frac{1}{3} \frac{D_{1}}{C_{11}}\left(C_{11} \underline{\alpha}_{1}+C_{12} \underline{\alpha}_{2}\right):\left(C_{11} \underline{\alpha}_{1}+C_{12} \underline{\alpha}_{2}\right) \\
& -\frac{1}{3} \frac{D_{2}}{C_{22}}\left(C_{12} \underline{\alpha}_{1}+C_{22} \underline{\alpha}_{2}\right):\left(C_{12} \underline{\alpha}_{1}+C_{212} \underline{\alpha}_{2}\right)+\frac{R_{1}^{2}}{2 Q_{11}}+\frac{R_{2}^{2}}{2 Q_{22}}-\frac{b_{11}^{2} Q_{11} r_{1}^{2}}{2}-\frac{b_{22}^{2} Q_{22} r_{2}^{2}}{2}
\end{aligned}
$$

with the quadratic form $\mathrm{G}$ which can be formulated as a function of the local stresses $\sigma_{\mathrm{i}}$ related to the two inelastic mechanisms $\varepsilon_{i} ; \mathrm{i}=1,2$.

$$
G=\sqrt{J_{2}\left(\sigma_{1}-\underline{X}_{1}\right)^{2}+J_{2}\left(\sigma_{2}-\underline{X}_{2}\right)^{2}}-R_{1}-R_{2}-R_{0}
$$

Evolution equations can be derived from equations (13-15).

$$
\begin{aligned}
& \dot{\varepsilon}_{i}=\frac{\partial \Omega}{\partial \underline{\sigma}_{i}}=\frac{3}{2} \dot{\lambda} \frac{\underline{\sigma}_{1}^{\prime}-\underline{X}_{1}^{\prime}}{\sqrt{J_{2}\left(\underline{\sigma}_{1}-\underline{X}_{1}\right)^{2}+J_{2}\left(\underline{\sigma}_{2}-\underline{X}_{2}\right)^{2}}} ; \mathrm{i}=1,2 \\
& \underline{\dot{\alpha}_{i}}=-\frac{\partial \Omega}{\partial \underline{\mathrm{X}_{\mathrm{i}}}}=\underline{\dot{\varepsilon}}_{1}-\frac{3}{2} \dot{\lambda} \frac{D_{i}}{C_{i i}} \underline{X}_{i}-\frac{3}{2} \frac{\underline{\mathrm{X}_{\mathrm{i}}}}{\underline{\mathrm{J}_{2}\left(\mathrm{X}_{\mathrm{i}}\right)}}\left\langle\frac{\mathrm{J}_{2}\left(\mathrm{X}_{\mathrm{i}}\right)}{\underline{\mathrm{M}_{\mathrm{i}}}}\right)^{\mathrm{m}_{\mathrm{i}}} \quad \text { and } \dot{\mathrm{r}}_{\mathrm{i}}=-\frac{\partial \Omega}{\partial R_{i}}=\dot{\lambda}\left(1-\frac{R_{i}}{Q_{i i}}\right) ; \mathrm{i}=1,2
\end{aligned}
$$

This formulation is also in a good agreement with thermodynamic principles, indeed, in this case, intrinsic dissipation remains positive:

$$
\Theta=\sum_{i=1}^{2}\left(\underline{\sigma}_{i}: \underline{\dot{\varepsilon}}_{i}-\underline{X}_{i}: \underline{\dot{\alpha}}_{i}-R_{i} \dot{r}_{i}\right)=\left(G+R_{0}\right) \dot{\lambda}+\sum_{i=1}^{2} \dot{\lambda}\left(\frac{D_{i}}{C_{i}} J_{2}\left(\underline{X}_{i}\right)^{2}+\frac{R_{i}^{2}}{Q_{i i}}+\underline{\mathrm{J}_{2}\left(\mathrm{X}_{\mathrm{i}}\right)}\left\langle\frac{\mathrm{J}_{2}\left(\mathrm{X}_{\mathrm{i}}\right)}{\mathrm{M}_{\mathrm{i}}}\right)^{\mathrm{m}_{\mathrm{i}}}\right) \geq 0
$$




\section{Plastic strain memorization.}

Experimental observations reported in the previous section give evidence of the softening dependence on initial plastic strain level. This effect can be introduced similarly in both of the previous formulations [1,4,5,24]. For that purpose, internal variables that memorise the prior maximal plastic strain range have to be implemented in the model. They use the memory surface in the plastic strain space first proposed by Ohno [29].

$$
F=\frac{2}{3} J_{2}\left(\underline{\varepsilon}_{p}-\underline{\xi}\right)-q
$$

$\underline{\xi}$ represents the centre of the memory surface and $\mathrm{q}$ its radius in the strain space. Plastic flow inside the strain domain (i.e. $\mathrm{F}<0$ ) does not change the "memory state". Evolution rules for q and $\underline{\xi}$ are:

$$
\dot{q}=\eta H(F)\left\langle\underline{n}: \underline{n}^{*}\right\rangle \dot{p} ; \quad \underline{\xi}=\sqrt{\frac{3}{2}}(1-\eta) H(F)\left\langle\underline{n}: \underline{n}^{*}\right\rangle \underline{n}^{*} \dot{p}
$$

where $\underline{n}$ and $\underline{n}^{*}$ are respectively the units normal to the yield surface $\mathrm{G}=0$ and to the memory surface $\mathrm{F}=0$.

$$
\text { Thus, } \underline{n}^{*}=\frac{\partial F}{\partial \underline{\varepsilon}_{p}} /\left|\frac{\partial F}{\partial \underline{\varepsilon}_{p}}\right|=\sqrt{\frac{3}{2}} \frac{\underline{\varepsilon}_{p}^{\prime}-\underline{\xi^{\prime}}}{J_{2}\left(\underline{\varepsilon}_{p}-\underline{\xi}\right)}
$$

and: $\underline{n}=\frac{\partial G}{\partial \underline{\sigma}} /\left|\frac{\partial G}{\partial \underline{\sigma}}\right|=\sqrt{\frac{3}{2}} \frac{\underline{\sigma}^{\prime}-\underline{X}}{J_{2}(\underline{\sigma}-\underline{X})}$ in the case of the first model formulation $[1,5,24]$,

and: $\underline{n}=\frac{\partial G}{\partial \underline{\sigma}} /\left|\frac{\partial G}{\partial \underline{\sigma}}\right|=\sqrt{\frac{3}{2}} \frac{A_{1}\left(\underline{\sigma}_{1}^{\prime}-\underline{X}_{1}^{\prime}\right)+A_{2}\left(\underline{\sigma}_{2}^{\prime}-\underline{X}_{2}^{\prime}\right)}{\sqrt{A_{1}^{2} J_{2}\left(\underline{\sigma}_{1}-\underline{X}_{1}\right)^{2}+A_{2}^{2} J_{2}\left(\underline{\sigma}_{2}-\underline{X}_{2}\right)^{2}+3 A_{1} A_{2}\left(\underline{\sigma}_{1}^{\prime}-\underline{X}_{1}^{\prime}\right):\left(\underline{\sigma}_{2}^{\prime}-\underline{X}_{2}^{\prime}\right)}}$ in the case of the second model formulation [1].

Following a previous work [3], the memory parameters $\mu$ is taken equal to 420 for all the temperature levels. Moreover, if only symmetrical strain controlled tests are considered, $\eta$ equals to 0.5 (instantaneous memorization) [4,24,29-30] and 0,1 for non-symmetrical tests [3]. This plastic softening memorization is used in the drag stress variable (equations 7 and 17) and it was shown [4] that the particular form $Q_{2}(q)=Q_{22}(q)=Q_{2 \infty}\left(1-e^{-2 \mu q}\right)$ may be used for martensitic steels.

\section{Results.}

In an unidirectional tensile-compressive configuration, the previous formulations can simplify to scalar state laws and evolution equations. These equation sets were considered to perform parameter identification of the different behavior models. The detailed identification process considering the previous experimental program can be found in the following references $[1,3,5,18,26]$.

For the first formulation, it was shown that most of the model parameters significantly evolve with tempering ratio and temperature except for $\mu$ (parameter related to strain memory) where a value of 420 is considered and for Young's modulus that evolves only with temperature. The following general expression allows to describe the temperature and ageing dependence of all model 
parameters, $P\left(T, \tau_{v}\right)=P_{0}(T)+P_{0}^{*}(T) .\left(1-\tau_{v}\right)$ except for $\mathrm{C}_{\mathrm{i}}, \mathrm{i}=1,2$ where a more complex expression is requested, $P\left(T, \tau_{v}\right)=P_{0}(T)+P_{0}^{*}(T) .\left(1-\tau_{v}\right)+P_{0}^{* *}(T)\left(1-\tau_{v}\right)^{2}$.

Last, a simplified equation can be used for kinematic hardening parameters $D_{i}, i=1,2$ and isotropic hardening $\mathrm{Q}_{1}$, as no temperature dependence was found $P\left(\tau_{v}\right)=P_{0}+P_{0}^{*} .\left(1-\tau_{v}\right)$.

Typical values identified at $\mathrm{T}=600^{\circ} \mathrm{C}$ are presented in table 2 and whole data base $\left(20^{\circ} \mathrm{C} \leq \mathrm{T} \leq\right.$ $600^{\circ} \mathrm{C}$ ) is available in $[3,5,26]$. Fig. 9 and 10 illustrate some results provided by the behavior model identified on AISI L6 martensitic steel.

\begin{tabular}{|c|c|c|c|c|c|c|c|c|c|c|}
\hline Coef. & $\begin{array}{c}\mathrm{K} \\
{[\mathrm{MPa} . \mathrm{s}]}\end{array}$ & $\mathrm{n}$ & $\begin{array}{c}\mathrm{C} 1 \\
{[\mathrm{MPa}]}\end{array}$ & $\begin{array}{c}\mathrm{C}_{2} \\
{[\mathrm{MPa}]}\end{array}$ & $\begin{array}{c}\mathrm{R}_{0} \\
{[\mathrm{MPa}]}\end{array}$ & $\mathrm{b}$ & $\begin{array}{c}\mathrm{Q}_{1} \\
{[\mathrm{MPa}]}\end{array}$ & $\begin{array}{c}\mathrm{Q}_{2 \propto} \\
{[\mathrm{MPa}]}\end{array}$ & $\mathrm{D}_{1}$ & $\mathrm{D}_{2}$ \\
\hline $\mathrm{P}_{0}$ & 195.35 & 1.01 & 25000 & 1366 & 203.23 & 4.87 & -1.35 & 17.8 & 250 & 81.17 \\
\hline $\mathrm{P}_{0}{ }^{*}$ & 1069.6 & 13.44 & $\begin{array}{c}1.1638 \\
10^{6}\end{array}$ & $\begin{array}{c}4.5702 \\
10^{4}\end{array}$ & -985.54 & -0.026 & -21.04 & 139.27 & 11515 & 877.44 \\
\hline $\mathrm{P}_{0}{ }^{* *}$ & $\sqrt{ }$ & $\sqrt{ }$ & $\begin{array}{c}5.6527 \\
10^{5}\end{array}$ & $\begin{array}{c}3.3440 \\
10^{5}\end{array}$ & $\sqrt{ }$ & $\sqrt{ }$ & $\sqrt{ }$ & $\sqrt{ }$ & $\sqrt{ }$ & $\sqrt{ }$ \\
\hline
\end{tabular}

Table 2 : Fatigue ageing model parameters $\left(\mathrm{T}=600^{\circ} \mathrm{C}\right)$ provided for the first model formulation

Fig. 9 shows a comparison of experimental and simulated stabilized fatigue loops for different strain rates and different initial hardness at $500^{\circ} \mathrm{C}$. Fig. 10 compares experimental and simulated cyclic softening for different initial hardness and two levels of testing temperatures. It was observed that simulated and experimental responses are in a good agreement, and, moreover, predictive capabilities were verified on samples with a hardness not included in identification testing base and also at temperature levels were ageing takes place during fatigue testing $[3,5,26]$.
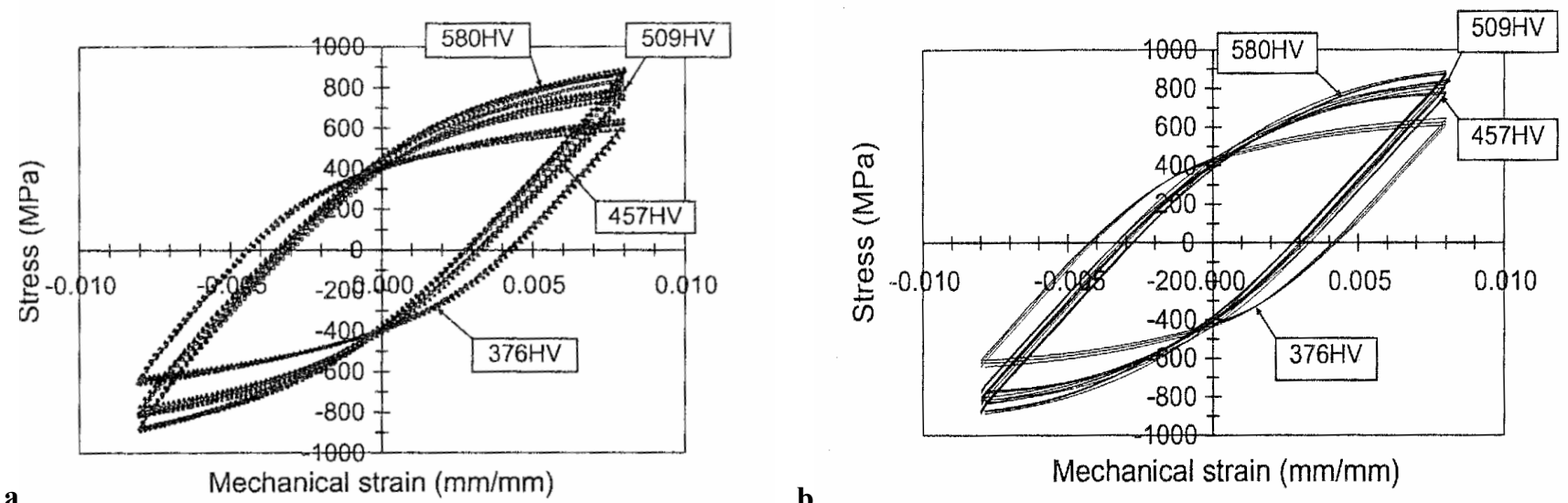

Figure 9: fatigue loops at $500^{\circ} \mathrm{C}$ (L6 steel) for 3 strain rates $\left(10^{-2} \mathrm{~s}^{-1}, 10^{-3} \mathrm{~s}^{-1}, 10^{-4} \mathrm{~s}^{-1}\right)$ and for 4 investigated initial hardness $(\Delta \varepsilon= \pm 0.8 \%)$ a- experimental, b- simulation
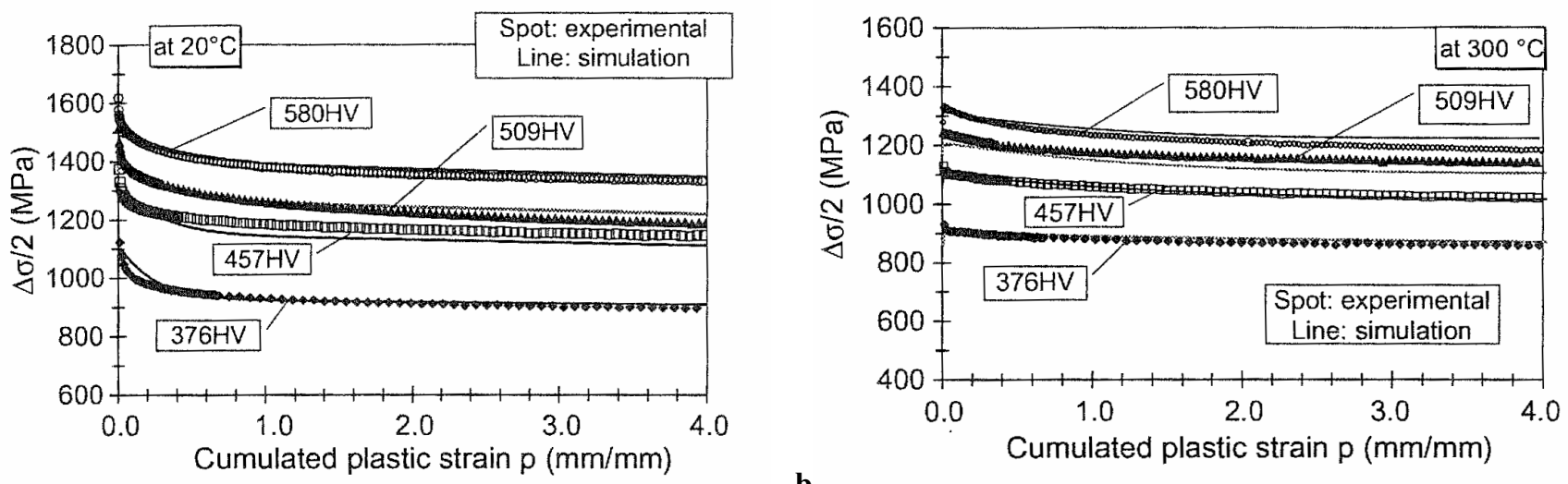

Figure 10: Stress amplitude versus cumulated plastic strain, experimental-simulation comparison: a- room temperature, $\mathbf{b}-\mathrm{T}=300^{\circ} \mathrm{C}$. 
The second model formulation was identified similarly [1,18,31]. Table 3 presents some values of the model parameters for both martensitic steels investigated at $\mathrm{T}=500^{\circ} \mathrm{C}$. In this case, the coupling of the back stresses allows the description of the elastic-to-viscoplastic transition without any dynamic recovery terms [1]. Thus, dynamic recovery terms were not considered in the identification process $\left(D_{i}=0 \quad i=1,2\right)$. Several previous papers present more deeply the complete identification methodology and provide more complete results for different levels of temperature [1,18,31]. Fig. 11 and 12 show model capabilities: Fig. 11a presents a comparison of the experimental and simulated fatigue loops including a tensile dwell time of $600 \mathrm{~s}\left(\mathrm{~T}=500^{\circ} \mathrm{C}, \mathrm{H} 11\right.$ steel). As it can be seen, the model is able to reproduce the significant stress relaxation activated at high temperature during dwell time. Fig. $11 \mathrm{~b}$ shows the plastic shakedown effect $\left(\mathrm{T}=500^{\circ} \mathrm{C}, \mathrm{H} 11\right.$ steel), whereas Fig. 12a illustrates the capabilities to describe the ratchetting effect $\left(\mathrm{T}=500^{\circ} \mathrm{C}\right.$, L6 steel). Last, the behavior model is also able to assess the continuous and multi-stage cyclic softening of the martensitic steel (Fig. $12 \mathrm{~b}$ for $\mathrm{H} 11$ steel at $\mathrm{T}=500^{\circ} \mathrm{C}$ ).

\begin{tabular}{|c|c|c|}
\hline Coefficients & AISI L6 & AISI H11 \\
\hline $\mathrm{E}[\mathrm{MPa}]$ & 157000 & 167760 \\
\hline $\mathrm{R}_{0}[\mathrm{MPa}]$ & 410 & 600 \\
\hline $\mathrm{K}[\mathrm{MPa} . \mathrm{s}]$ & 268 & 455 \\
\hline $\mathrm{n}$ & 15 & 6 \\
\hline $\mathrm{C}_{11}[\mathrm{MPa}]$ & 195655 & 210665 \\
\hline $\mathrm{C}_{22}[\mathrm{MPa}]$ & 13215 & 6975 \\
\hline $\mathrm{C}_{12}[\mathrm{MPa}]$ & -40500 & -8065 \\
\hline $\mathrm{A}_{1}$ & 0.65 & 0.5 \\
\hline $\mathrm{A}_{2}$ & 0.48 & 0.77 \\
\hline $\mathrm{M}_{1}$ & 705 & 640 \\
\hline $\mathrm{m}_{1}$ & 10.5 & 6 \\
\hline $\mathrm{M}_{2}$ & 700 & 520 \\
\hline $\mathrm{m}_{2}$ & 4.3 & 4 \\
\hline $\mathrm{Q}_{1}[\mathrm{MPa}]$ & -75 & -132 \\
\hline $\mathrm{b}_{1}$ & 0.2 & 0.3 \\
\hline $\mathrm{Q}_{2 \alpha}[\mathrm{MPa}]$ & -100 & -137 \\
\hline $\mathrm{b}_{2}$ & 5.5 & 4.5 \\
\hline
\end{tabular}

Table 3 : Fatigue model parameters $\left(\mathrm{T}=500^{\circ} \mathrm{C}\right)$ provided for the $2 \mathrm{M} 1 \mathrm{C}$ model formulation.

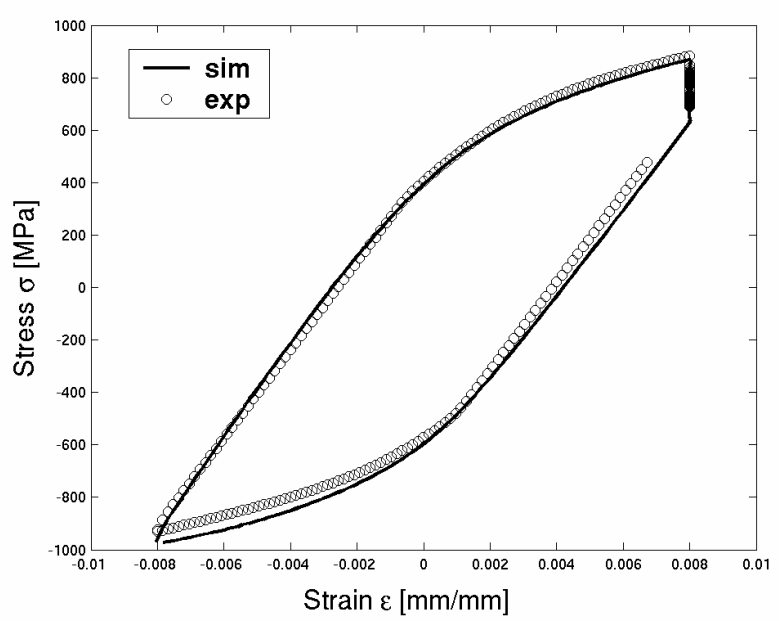

Figure 11: a- Experimental-simulation comparison with a dwell time of $600 \mathrm{~s}\left(\mathrm{~T}=500^{\circ} \mathrm{C}, \mathrm{H} 11\right.$ steel $)$

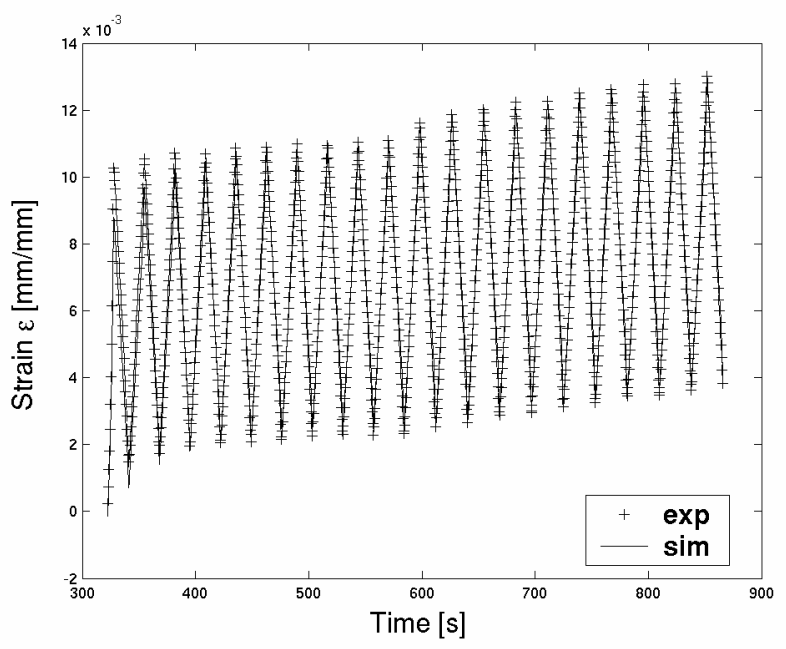

b- Experimental-simulation strain amplitude comparison - description of the plastic shakedown effect $\left(\mathrm{T}=500^{\circ} \mathrm{C}, \mathrm{H} 11\right.$ Steel) 
The Two Mechanisms and one Criterion (2M1C) model provides a non-unified approach through the yield criterion, and the two stress states induced by two different strain mechanisms can be related to the two main micro-structural evolutions observed: the carbide coarsening and the decrease of the dislocation density [8]. The quenching generates a high dislocation density within the martensitic laths. The cyclic load leads to an increase of the mean free motion of the dislocations. The rearrangement mechanism is the most important observed on the tempered martensitic steel [8]. In the formulation, it is represented through the isotropic variable $\mathrm{R}_{2}$ (and the strain mechanism $\varepsilon_{2}$ ) that describes the strong softening during the first hundred of cycles. The variable $\mathrm{R}_{1}$ (and strain mechanism $\varepsilon_{1}$ ) represents the continuous linear softening and is attributed to the carbide coarsening mechanism. As a matter of fact, the increase of the test time induces a carbide coarsening which increases the dislocation free motion path and leads to a continuous softening. In order to give a microstructural validation of this model, the relative level of these mechanisms on the cyclic softening amplitude was determined experimentally on a fatigue test sample performed at a temperature of $550^{\circ} \mathrm{C}$. It was found that one third is due to the carbide coarsening and two third due to the dislocation motion [8]. A similar ratio was obtained with the 2M1C model, and we feel that such models may represent interesting tools to improve the knowledge of the micro-structural evolutions during fatigue and give information for material improvement in relation with high temperature fatigue.

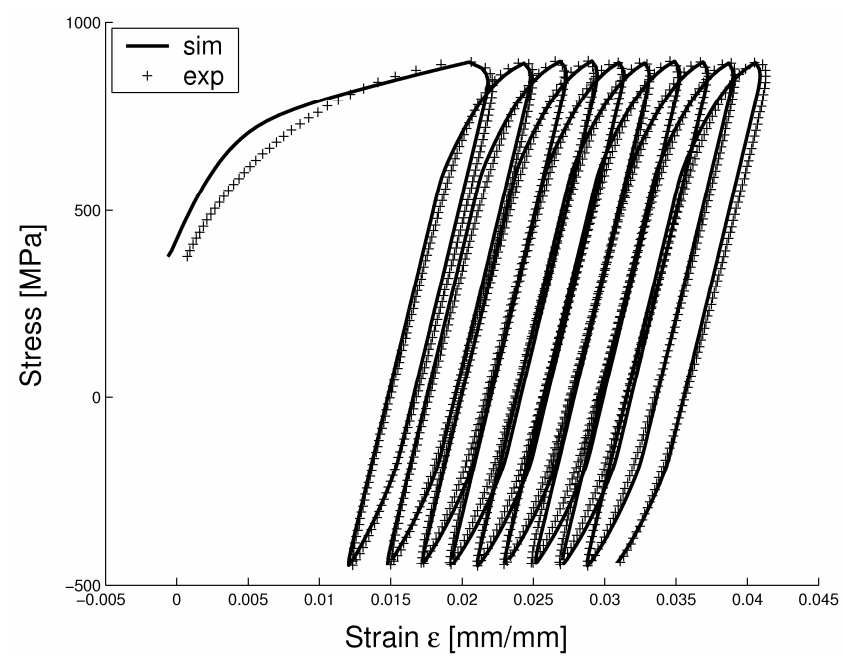

Figure 12: a- Experimental-simulation strainstress curves comparison - description of the ratchetting effect $\left(\mathrm{T}=500^{\circ} \mathrm{C}\right.$, L6 steel)

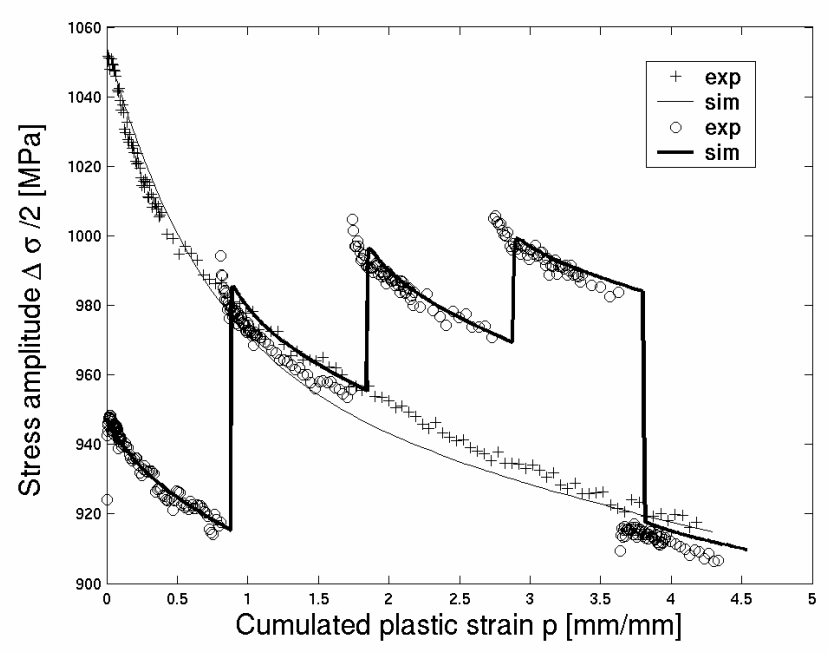

b- Experimental-simulation cyclic softening comparison for a continuous and multi-stage softening $\left(\mathrm{T}=500^{\circ} \mathrm{C}, \mathrm{H} 11\right.$ steel $)$

\section{Lifetime model.}

Fatigue resistance is determined by the material lifetime through the number of cycles to failure. Usually stress is the critical value and is plotted versus the number of cycles to failure in the Woehler representation. Three major domains are considered :

- Low cycle fatigue domain (domain 1) for very high stress amplitudes and a number of cycles to failure until $5.10^{4}$ cycles.

- Limited high cycle fatigue domain (domain 2) for lower stress amplitudes and a number of cycles to failure between $5.10^{4}$ and $5.10^{6}$ cycles.

- Unlimited high cycle fatigue domain (domain 3) for very low stress amplitude and a number of cycles to failure between $10^{7}$ and $10^{9}$ cycles.

The fatigue investigations reported are relative to the first and the beginning of the second domain, as the number of cycles before an irreversible damage of the hot forming tools is generally lower 
than $10^{5}$ cycles for AISI H1 1 and L6 steels. The continuous cyclic softening of the martensitic steels till rupture does not allow to define a stabilized cycle in order to plot the Woehler curves, so a pseudo stabilized cycle is selected at mid-life.

Non linear continuum damage models include in general two components:

- Fatigue damage that can be expressed with the number of cycles $d D=f\left(\sigma_{M}, \sigma_{\text {mean }}, D\right) d N$.

- Creep damage that describes the time dependent mechanisms and is formulated with time. Its calculation is done by integrating an equivalent mean stress over a cycle.

As no significant creep rupture mechanisms were observed during fracture analysis [17,19-20], it was assumed that this mechanisms is negligible in comparison with the fatigue damage one. If only fatigue damage component is activated, the fatigue model takes into account the characteristic values of a fatigue cycle, i.e. maximal stress $\sigma_{M}$ or semi-stress amplitude $\Delta \sigma / 2$ and mean stress $\bar{\sigma}$. Several evolution laws were formulated to describe the damage variation from 0 to 1 [32-33]. However, experimental damage investigations performed on most of materials have shown a damage rate equals to zero at the very beginning of the test that increases rapidly near rupture (and comes close to infinite). Therefore, the following form [12, 34-35] was usually adopted for the damage law:

$$
d D=\left(1-(1-D)^{\beta+1}\right)^{\alpha}\left(\frac{\Delta \sigma}{2 M\left(\sigma_{\text {mean }}\right)} / 1-D\right)^{\beta} d N
$$

Parameter $\alpha$ describes the fatigue damage accumulation that can be considered linear if $\alpha$ is taken as a loading independent parameter or non linear if $\alpha$ is taken as a loading dependent parameter [11]. In this last case, different expressions are available to define this coefficient [12], but most of them consider the fatigue limit and the maximal stress. Nowadays, the following form is commonly used for metallic materials:

$\alpha=1-a \frac{\left\langle\sigma_{M}-\sigma_{l}\right\rangle}{\left\langle\sigma_{u}-\sigma_{M}\right\rangle}$; with $\sigma_{l}$ and $\sigma_{\mathrm{u}}$ are respectively the fatigue limit and the ultimate tensile stress of the material.

If only fatigue damage occurs, integration of damage variable between 0 (virgin material) and 1 (macro crack initiation) provides the number of cycles to failure of the representative volume element. The following expression is obtained:

$$
N_{R}=\frac{1}{a(\beta+1)} \frac{\left\langle\sigma_{u}-\sigma_{M}\right\rangle}{\left\langle\sigma_{M}-\sigma_{l}\right\rangle}\left(\frac{\Delta \sigma}{2 M}\right)^{-\beta}
$$

Moreover, fatigue damage evolution can be formulated with respect to the ratio number of cycles versus number of cycles to failure:

$$
d D=1-\left(1-\left(\frac{N}{N_{R}}\right)^{\frac{1}{1-\alpha}}\right)^{\frac{1}{1+\beta}}
$$

In introducing the reduced stress $S=\frac{\sigma}{\sigma_{u}}$, obtained by dividing the mechanical parameters by the ultimate stress at corresponding temperature, such a model is also valid when the temperature 
evolves within the mechanical cycle (thermal or thermo-mechanical fatigue). Thus, previous equations can be written as:

$$
d D=\left(1-(1-D)^{\beta+1}\right)^{\alpha}\left(\frac{\Delta S}{2 M} / \frac{1-D}{\sigma_{u}}\right)^{\beta} d N \quad \text { and } \quad N_{R}=\frac{1}{a(\beta+1)} \frac{\left\langle 1-S_{M}\right\rangle}{\left\langle S_{M}-\sigma_{l} / \sigma_{u}\right\rangle}\left(\frac{\Delta \sigma}{2 M}\right)^{-\beta}
$$

\section{Results.}

From equation (25), model parameters are determined by plotting the Woehler curves in a bilogarithmic diagram:

$$
\log \left(\frac{\Delta S}{2}\right)=Y_{0}-\frac{1}{\beta} \log \left(g\left(N_{R}\right)\right) \quad \text { where } \quad \mathrm{g}\left(\mathrm{N}_{\mathrm{R}}\right)=\frac{\left\langle S_{M}-\frac{\sigma_{l}}{\sigma_{u}}\right\rangle}{\left\langle 1-S_{M}\right\rangle} N_{R} .
$$

Thus, only one set of parameters has to be determined for all the temperature levels. Slope and intersection of the straight line with $\mathrm{Y}$-axis allow identification of $\beta$ and

$$
Y_{0}=\frac{1}{\beta} \log \left(\left(\frac{M}{\sigma_{u}}\right)^{\beta} / a(1+\beta)\right) .
$$

Identified values obtained are $\beta=12$ and $\mathrm{Y}_{0}=-0.335$. Moreover, a classical value for the metallic materials of 0.3 is considered for the fatigue limit ratio over ultimate stress $\sigma_{\mathrm{l}} / \sigma_{\mathrm{u}}$.

Fig. 13a presents Woehler master curve of the AISI H11 steel. As expected, all the test results are on a same straight line whatever the test conditions (temperature, strain rates, dwell times) confirming that only fatigue damage occurs. So, it is concluded that, for the test conditions considered close to those applied in the hot forming processes, AISI H11 steel is not affected by creep damage but only by fatigue damage. These results are in a good agreement with the SEM observations [19-20]. Fig. 13b compares experimental and calculated lifetimes. Numbers of cycles to failure are assessed for all the fatigue tests within a scattering factor 2 on lifetimes which is usually accepted in low cycle fatigue. This point is more slightly discussed in previous works [1718]. This approach was also successfully applied to assess lifetimes of thermo mechanical fatigue tests $[17-18,20]$. 


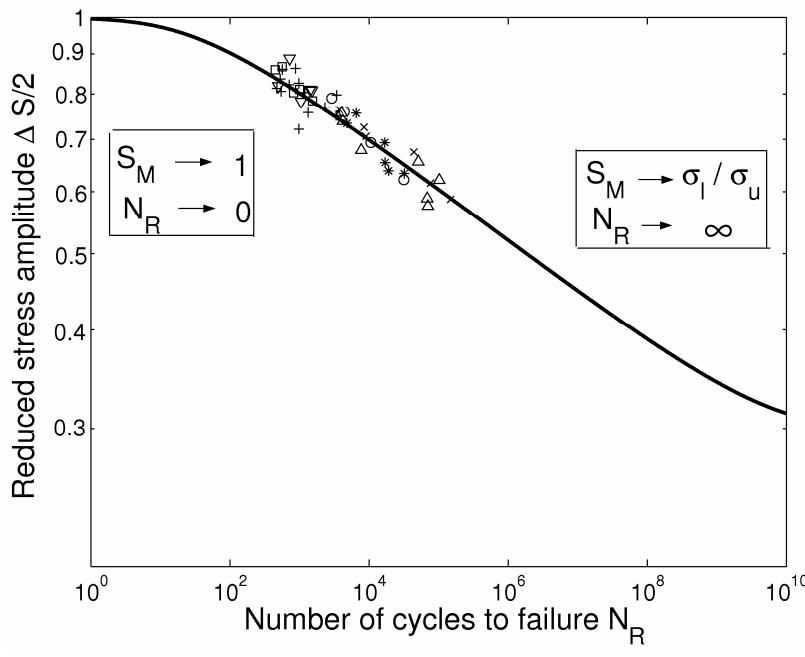

Figure 13: a- Normalized Woehler curve diagram including all the fatigue database

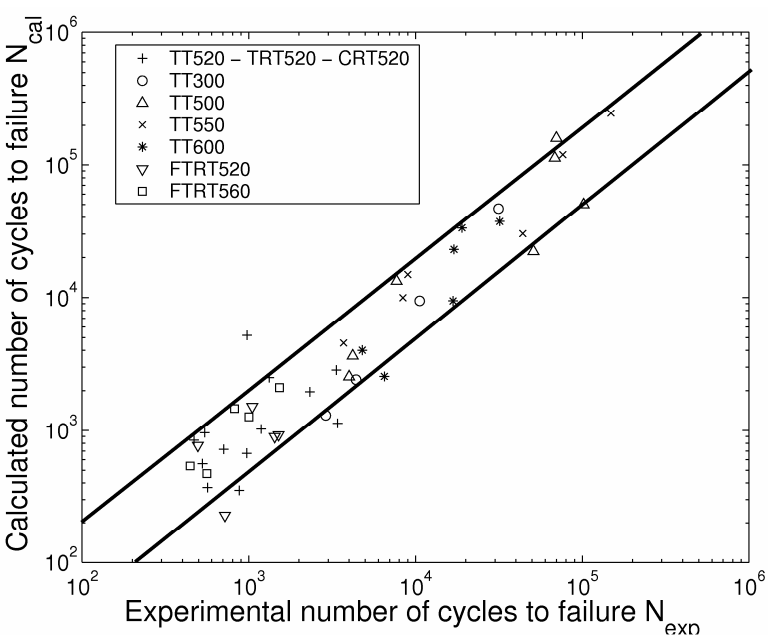

b- Comparison between experimental and calculated number of cycles to failure

\section{Conclusion}

This paper presents a robust fatigue behavior and lifetime methodology developed during the last years on tempered martensitic steels. It is based on constitutive behavior laws to evaluate the stressstrain response of the material combined with a continuum damage model to assess the number of cycles to failure. This approach was successfully applied on martensitic hot work tool steels for uniaxial, isothermal and non isothermal conditions. It allows to take into account a great number of test conditions (different strain rates, strain amplitudes, temperature levels). The lifetime model can be connected to two different behavior laws able to take into account, on the one hand, the microstructure evolution induced by time-temperature ageing and on the other hand, very complex loading paths (dwell times, plastic shakedown or ratchetting effects) by the introduction of two inelastic mechanisms related to microstructural evolutions responsible to the cyclic softening. Both models have required a deep knowledge of microstructural evolution during tempering and fatigue as well as stress strain responses under iso-thermal and thermo-mechanical fatigue loading paths. The complete methodology has been validated on isothermal and thermomechanical fatigue tests $[3,5]$ and on structural specimens [1,31]. For that purpose, important numerical developments were also performed in order to implement these approaches in a finite element code $[1,18]$.

\section{References.}

[1] V. Velay, G. Bernhart and L. Penazzi: International Journal of Plasticity Vol. 22 (2006), p. 459.

[2] Z. Ahmer, V. Velay, G. Bernhart and F. Rezai-Aria: proceedings of the $7^{\text {th }}$ Tooling Conference, Torino, Italy (2006).

[3] Z. Zhang, D. Delagnes and G. Bernhart : International Journal of Fatigue Vol. 24 (2002), p. 635.

[4] G. Bernhart, G. Moulinier, O. Brucelle and D. Delagnes: International Journal of Fatigue Vol. 21, n² (1999), p.179

[5] Z. Zhang, G. Bernhart and D. Delagnes: International Journal of Fatigue, article in press (2007).

[6] S. Bari and T. Hassan: Intenational Journal of Plasticity, Vol. 18, (2002), p. 873.

[7] L. Vincent, S. Calloch and S. Marquis: International Journal of Plasticity, Vol. 20, (2004), p. 1817. 
[8] N. Mebarki, D. Delagnes, P. Lamesle, F. Delmas and C. Levaillant: Materials Science Engineering A, Vol. 387-389, (2004) p. 171.

[9] G. Cailletaud and K. Sai: International Journal of Plasticity, vol. 23(9), 2007, p. 1589.

[10] G. Cailletaud and K. Sai: International Journal of Plasticity, Vol. 11, (1995), p. 991.

[11] J. Lemaître, J-L. Chaboche, Mechanics of solid materials, Cambridge University Press (1994).

[12] J.L. Chaboche and P.M. Lesne: Fatigue and Fracture of Engineering Materials and Structures, Vol. 11, (1998) p. 17.

[13] E. Nicouleau-Bourles : PhD thesis, Ecole Nationale Supérieure des Mines de Paris, (1999).

[14] F. Gallerneau : PhD thesis, Ecole Nationale Supérieure des Mines de Paris (1995).

[15] N .Mebarki : PhD Thesis, Ecole Nationale Supérieure des Mines de Paris, (2003).

[16] P. Michaud, D.Delagnes, P. Lamesle, M.H. Mathon and C. Levaillant, Acta Materialia, Vol. 55, (2007), p. 4877.

[17] V. Velay, G. Bernhart, D. Delagnes and L. Penazzi: Fatigue and Fracture of Engineering Materials and Structures Vol. 28, (2005) p. 1009.

[18] V. Velay : PhD thesis, Ecole Nationale Supérieure des Mines de Paris, (2003).

[19] D. Delagnes : PhD thesis, Ecole Nationale Supérieure des Mines de Paris, (1998).

[20] A. Oudin : PhD thesis, Ecole Nationale Supérieure des Mines de Paris, (2001).

[21] S. Arnold, A. Saleeb and T. Wilt: Journal of Engineering Materials and Technology, Vol. 117, (1995) p.157.

[22] B. Halphen and Q. Nguyen: Mechanics Research Communication Vol. 1 (1974) p. 43.

[23] A. Benallal and D. Marquis: Journal of Engineering Materials and Technology, Vol. 109 (1987) p.326.

[24] J.L. Chaboche: International Journal of Plasticity, Vol. 5, (1989) p.247.

[25] S. Bodner: Unified Constitutive Equations for Creep and Plasticity, Elsevier Applied Science, London (1987).

[26] Z. Zhang: PhD thesis, Ecole Nationale Supérieure des Mines de Paris, (2002).

[27] J.L. Chaboche, N. El Mayas and P. Paulmier: CR Acad. Sci. Paris, Vol 320, (1995) p. 9.

[28] J.L. Chaboche: La recherche Aérospatiale, Vol. 5, (1983), p.363.

[29] N. Ohno: Journal of Applied Mechanics, Vol. 49, (1982) p. 721.

[30] D. Nouailhas, D. policella, H. Kaczmarek: International Conference on Constitutive laws for Engineering Materials, Elsevier, Tuscon, Arizona (1983), p. 45.

[31] V. Velay, G. Bernhart, Z. Zhang and L. Penazzi: CAMP2002, high temperature fatigue, Paderborn, Germany (2002), p.64.

[32] J.L. Chaboche: Revue française de Mécanique, (1974), p50.

[33] J.L. Chaboche and P.M. Lesne: Fatigue and Fracture of Engineering Materials and Structures, Vol. 11(1), (1988), p. 1.

[34] J.L Chaboche, H. Kaczmarek and P. Raine: La recherche Aérospatiale, (1980), p. 177.

[35] E. Nicouleau-Bourles: PhD thesis Ecole Nationale Supérieure des Mines de Paris, (1999). 